\title{
Mid-year at the FDA highlights permanent problem
}

Approval numbers at this stage tell less of a story than the pitfalls of a potential leadership vacuum.

\section{Ken Howard}

The sigh of relief given by the industry at the slight upturn in the number of approvals of new molecular entities (NMEs) in 2003 became somewhat muted with the departure of the FDA commissioner, who is widely credited with trying to make the approval process more efficient. So, can any conclusions be drawn about the slight dip in NMEs and biopharmaceuticals now under the remit of Center for Drug Evaluation and Research (CDER) that have been approved at the midway stage in 2004 thirteen drugs - compared with fourteen at the same point in 2003 ?

One disappointment is that the degree of innovation that shone through the list of approvals in 2003, which included drugs such as enfuvirtide (Fuzeon; Roche/ Trimeris), gefitinib (Iressa; AstraZeneca) and bortezomib (Velcade; Millennium) does not appear to have been maintained in the drugs approved so far this year. (For a full list of approved drugs, see http://www.fda.gov/cder/rdmt/)

Apart from that, there are not many conclusions that can be drawn from these figures, according to industry watchers.

On the face of it, the approval numbers are a movement in the right direction, says David Flockhart, professor of medicine and pharmacology at Indiana University School of Medicine. But the current approvals reflect what the FDA was doing

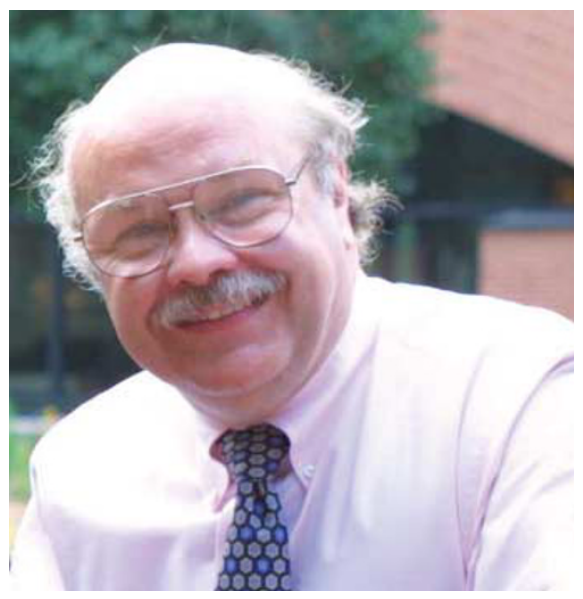

David Flockhart: approval numbers are a step in the right direction. approximately four years earlier, as there is always a delayed effect between the review process and ultimate approvals. As such, this year's numbers might not say much about approval rates in the future.

Henry Miller, a research fellow at the Hoover Institution at Stanford University and a former director of the FDA's Office of Biotechnology, is blunter: he says trying to predict end-of-year numbers or even rate trends on the basis of mid-year approvals is nothing more than hand waving. A doubling from mid-point can't be assumed, he says. He also says that recent annual approval numbers represent too small a sampling to show a reversal in an overall decrease in approval numbers since 1996.

A more important long-range predictive number, say Miller and Flockhart, is the number of unfilled permanent positions in top FDA positions, including 'acting' designations for commissioner, deputy commissioner for operations, and director and deputy director positions in CDER.

\section{"'Acting' is a major problem. A good commissioner can lead industry in innovation. Not filling [the position] is criminal."}

This is "not a healthy situation," says Miller, arising from the "refreshing but not altogether forthright" approach of former commissioner Mark McClellan, who left in March this year. "McClellan denied that the FDA had a problem and emphasized communication with industry," says Miller. “That's not what's needed. What's needed is a stick to whip the FDA's risk-aversive personnel into a less defensive posture," as this causes unnecessarily long waits for approvals. That stick, he says, is leadership.

As a permanent leader, McClellan did spur some movement within the FDA ranks for getting approvals made faster, admits Miller. His influence could be seen last December, at a time of year when there is a characteristic increase in the number of approvals relative to other months. December 2003, by contrast, saw only one approval. "The approvers were trying to look good for McClellan [in 2003], and by December there was nothing left, no applications languishing

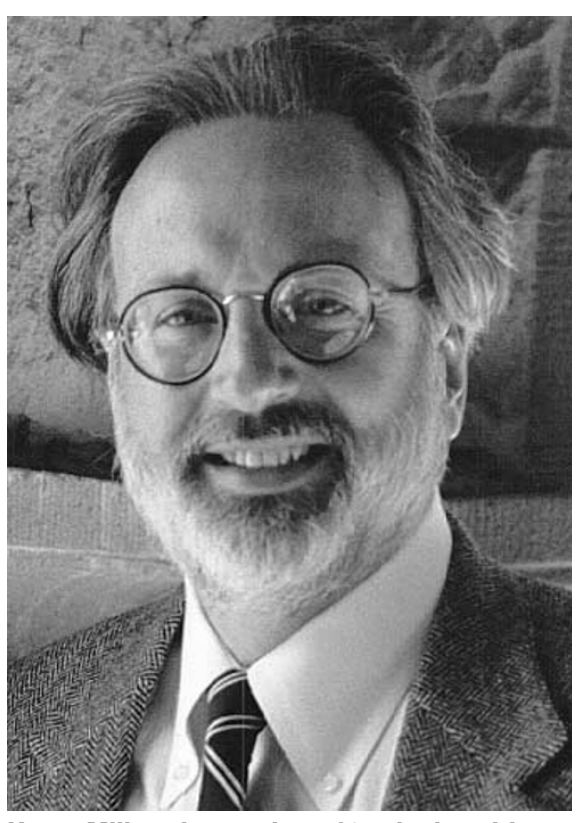

Henry Miller: the number of 'acting' positions is not a healthy situation for the FDA.

that just needed external impetus to get out," says Miller.

FDA spokesperson Larry Bachorik said that the FDA is actively searching for candidates, and acting commissioner Lester Crawford has been conducting interviews. But there is no time limit for when the acting positions must be filled permanently, so it is "hard to say" when the positions might be filled. The commissioner position is appointed by the White House and then confirmed by the Senate, so it will be up to the president to advance a name for the permanent position. As this is an election year, it is generally thought that even the search for a new commissioner will be delayed until after the identity of the next administration is determined.

But will this be too long a hiatus? Maintaining the momentum initiated by McClellan requires a permanent commissioner, says Flockhart. "'Acting' is a major problem. A good commissioner can lead industry in innovation. Not filling [the position] is criminal."

For more news and analysis go to news@nature.com www.nature.com/news 